\title{
FILOSOFIA NATURAL E IMATERIALIDADE EM TOMÁS DE AQUINO
}

Natural philosophy and immateriality in Thomas Aquinas

Evaniel Brás dos Santos *

Resumo: O presente estudo investiga se, para Tomás de Aquino, a filosofia natural enquanto matriz disciplinar faz referência à imaterialidade. Para tanto, inicialmente é discutida a questão sobre a relação entre a filosofia natural e a imaterialidade a partir da temática que aborda a locomoção celeste. Posteriormente, o estudo se concentra na diferença entre a filosofia natural de Tomás e a filosofia natural de Aristóteles. Enfim, o texto conclui mostrando a razão central pela qual a filosofia natural de Tomás requer que o primum principium motus seja imaterial e eficiente.

Palavras-chave: Filosofia natural. Imaterialidade. Movimento. Metafísica. Tomás de Aquino.

Abstract: The present study investigates whether, for Thomas Aquinas, natural philosophy as a disciplinary matrix refers to immateriality. In order to do so, the relation between natural philosophy and immateriality is first discussed based on the question of celestial locomotion. Subsequently, the study focuses on the difference between Thomas Aquinas' natural philosophy and Aristotle's natural philosophy. Finally, it shows the central reason why the author's natural philosophy requires the primum principium motus to be immaterial and efficient.

Key-words: Natural philosophy. Immateriality. Movement. Metaphysics. Thomas Aquinas.

* Doutor em Filosofia pela UNICAMP. Pesquisador do grupo de pesquisa "Metafísica e Política" (UNICAMP). Participa como integrante do projeto "Movimento e Matéria Celeste no Argumento pela Eternidade do Mundo", financiado pelo CNPq. 


\section{Introdução}

questão central investigada neste artigo procura saber se a filosofia
natural enquanto matriz disciplinar se refere ao imaterial, conforme
Tomás de Aquino (1225-1274). ${ }^{1}$

A questão torna-se mais emblemática pela constatação segundo a qual Tomás não estabeleceu um tratamento sistemático de filosofia natural (philosophia naturalis), também designada de ciência natural (scientia naturalis) e física (physica).

Enquanto ciência, a filosofia natural necessita de um sujeito (subiectum) e de um objeto (materia). O sujeito da ciência é aquilo que é tomado como evidente por ela, pois "[...] nenhuma ciência prova seu sujeito". ${ }^{2} \mathrm{O}$ objeto da ciência, por sua vez, é o assunto central investigado por ela. O sujeito da ciência natural é o "[...] ente móvel considerado de modo simples", ${ }^{3}$ ou seja: "[...] o movido na medida em que é móvel". ${ }^{4}$ A referência ao ente móvel (ens mobile) visa acenar para o aspecto de universalidade ou de matriz disciplinar da filosofia natural, razão pela qual ela deve ser entendida como uma ciência geral e integral. A generalidade da filosofia natural decorre do fato de ela ser a ciência teórica que, depois da metafísica, aborda o ente do modo mais universal possível. A integralidade da filosofia natural, por outro lado, diz respeito à constatação segundo a qual outras ciências naturais menos gerais tratam de determinados entes. Tais ciências, ademais, pressupõem a filosofia natural, estando unidas a ela.

Os estudos sobre a filosofia natural de Tomás cresceram de modo significativo ao longo do século XX. Tais estudos podem ser divididos em dois grupos: (a) um que investiga os critérios de cientificidade da filosofia natural, investigação pertencente à discussão geral sobre a classificação das ciências e, outro, (b) que investiga as teses centrais desta ciência, como as definições de cosmo e natureza, além do gênero movimento. O segundo grupo, que é o que interessa aqui, cresceu razoavelmente a partir da década de cinquenta do século XX. Uma subdivisão pode ser feita no segundo grupo, qual seja, por um lado (b.1) os estudos mais gerais que pretendem contemplar a filosofia natural como um certo sistema; por outro, (b.2) os estudos mais pontuais que investigam determinadas teses da filosofia natural.

\footnotetext{
${ }^{1}$ As obras de Tomás serão referenciadas do seguinte modo: SLSPL (Scriptum Super Libros Sententiarum Magistri Petri Lombardi); ST (Summa Theologiae); SCG (Summa contra gentiles); In Physicorum (In octo libros physicorum Aristotelis expositio; In DCM (In libros Aristotelis De caelo et mundo); SBDT (Super Boetium De Trinitate); QDP (Quaestiones Disputatae de Potentia Dei); DSC (Quaestio Disputata de Spiritualibus Creaturis).

2 THOMAS AQUINAS, In octo libros physicorum Aristotelis expositivo, 1884, I, 1, n. 4: “[...] nulla autem scientia probat suum subiectum".

${ }^{3}$ THOMAS AQUINAS, 1884, I, 1, n. 4: "[...] ens mobile simpliciter".

${ }^{4}$ THOMAS AQUINAS, In libros Aristotelis de caelo et mundo, 1886, I, prooemium, n. 3: “[...] mobili inquantum est mobile".
} 
Dentre os estudos mais gerais (b.1), pode-se mencionar os estudos de Cornoldi (1893), ${ }^{5}$ McWilliams (1945), ${ }^{6}$ Elders (1994), ${ }^{7}$ bem como a produção bibliográfica tomada em conjunto dos membros da River Forest. ${ }^{8}$ Por outro lado, dentre os estudos mais pontuais (b.2), dois subgrupos se destacam. Um que trata sobre a definição de natureza, seja como uma descrição geral, como ocorre com Beavers ${ }^{9}$ e Elders ${ }^{10}$, seja como uma análise aprofundada, como é o caso de Weisheipl, ${ }^{11}$ Aertsen, ${ }^{12}$ Lang $^{13}$ e Twetten ${ }^{14}$. O outro, por sua vez, aborda justamente o quesito sobre a referência ou não da filosofia natural ao imaterial. Knasas aparece como aquele que mais tem se dedicado à essa temática e, consequentemente, tem sido alvo de muitas críticas. Desde 1987 até 2003, Knasas sustenta que a filosofia natural de Tomás não faz referência à imaterialidade. Jonhson, Ashley e Kondoleon, por outro lado, criticam os argumentos de Knasas e sustentam não só que a filosofia natural refere-se à imaterialidade, mas também que ela prova a existência divina. Dewan, sem mencionar os estudos de Knasas, se volta contra Ashley (e Weisheipl) criticando seus argumentos e negando a prova mencionada. ${ }^{15}$

${ }^{5}$ CORNOLDI, G. M. The Physical System of St. Thomas, 1893.

${ }^{6}$ MCWILLIAMS, J. A. Physics and philosophy: a study of Saint Thomas' commentary on the eight books of Aristotle's Physics, 1945.

${ }^{7}$ ELDERS, L. J. La philosophie de la nature de Saint Thomas d'Aquin, 1994.

${ }^{8}$ Fundada em 1939 em Illinois (Estados Unidos) a River Forest sustenta a tese magna segundo a qual há uma "perene tradição aristotélica" na história da filosofia e da ciência. Dentre seus membros mais conhecidos encontram-se Weisheipl, Wallace, Ashley e Kondoleon. Para uma apresentação introdutória das teses "aristotélicas" defendidas pela escola, ver: ASHLEY, B. M. The River Forest School and the Philosophy of Nature Today, in: LONG, R. J. (ed.). Philosophy and the God of Abraham, 1991,. p. 1-15. Para o conteúdo propriamente das teses "aristotélicas", ver os textos de Weisheipl, Ashley e Kondoleon incluídos na bibliografia.

9 BEAVERS, A. F. Motion, Mobility, and Method in Aristotle's "Physics", The Review of Metaphysics,1988, p. 357-374.

${ }^{10}$ ELDERS, St. Thomas Aquinas's Commentary on Aristotle's Physics. Review of Metaphysics, 2013, p. 713-748.

${ }^{11}$ Ver as obras deste autor citadas na bibliografia.

${ }^{12}$ AERTSEN, J. A. Nature and Creature: Thomas Aquinas's Way of Thought. 1988.

${ }^{13}$ LANG, Helen. S. Thomas Aquinas and the Problem of Nature in Physics II, 1. History of Philosophy Quarterly, 1996, p. 411-432.

${ }^{14}$ Dentre os estudiosos mencionados neste artigo, Weisheipl, Aertsen e Twetten merecem destaque porque abordam com profundidade, no âmbito da cosmologia, a articulação entre a causa eficiente e a locomoção natural do cosmo. Twetten parece superar os outros porque, a meu ver, percebeu e abordou, sob influência explícita de Owens, a íntima relação entre a causa essendi e a causa da locomoção do cosmo entendido como o conjunto dos corpos simples. Ver suas obras citadas na bibliografia.

${ }^{15}$ Ver KNASAS, J. F. X. Ad Mentem Thomae Does Natural Philosophy Prove God? Proceedings of the American Catholic Philosophical Association,1987, p. 209-220 e IDEM, Immateriality and Metaphysics. Angelicum, 1988, p. 44-76. Em tais textos, o autor se esforça por mostrar que a filosofia natural de Tomás não prova a existência divina. Insatisfeito com os argumentos de Knasas, Jonhson escreve contra ele; ver. JONHSON, M. F. St. Thomas's De trinitate, Q. 5, A. 2, ad 3: A Reply to John Knasas. The New Scholasticism, 1989, p. 58-65. A resposta de Knasas aparece em seguida: KNASAS, “Does Natural Philosophy Prove the Immaterial?": An Answer to Mark Johnson. American Catholic Philosophical Quarterly,1990, p. 265-269. Johnson volta a criticar Knasas e a reafirmar sua posição ainda em 1990: JONHSON, Immateriality and the Domain of Thomistic Natural Philosophy. The Modern Schoolman, 1990, 
No interior da obra de Tomás, a noção de imaterialidade pode possuir quatro referencias, quais sejam: Deus, as inteligências separadas, a alma intelectiva humana e a força universal cósmica ${ }^{16}$. É certo que uma parte da filosofia natural refere-se à alma intelectiva, a saber, a psicologia. Aí, entretanto, a investigação ocorre por uma ciência determinada no âmbito geral da filosofia natural. É necessário, todavia, saber se a filosofia natural enquanto matriz disciplinar, ou seja, na medida em que é considerada como ciência geral e integral, há referência à imaterialidade e, se houver, qual o referencial. Para tanto, é possível tomar como ponto de partida a leitura da Physica II, 1 de Aristóteles empreendida por Tomás. ${ }^{17}$

O procedimento de Tomás ao ler a Physica II, 1, nomeadamente quanto à definição clássica de natureza de Aristóteles - princípio de movimento e repouso - é marcado por dois passos significativos, a saber: pela introdução das expressões corpos celestes (corpora caelestia) e motor separado (motor separatus). ${ }^{18}$ É intrigante a introdução de tais expressões, sobretudo se se

p. 285-304. No ano seguinte, Knasas responde as críticas de Johnson: KNASAS, Materiality and Aquinas' Natural Philosophy. A Reply to Johnson. Modern Schoolman, 1991, p. 245-257. Os pontos centrais dos argumentos de Knasas, incluindo suas críticas a outros tomistas, encontram-se de modo sistemático em seu livro: KNASAS, Being and Some Twentieth-Century Thomists, 2003. Ashley em 2006 se volta contra os argumentos de Knasas presentes no livro mencionado; ver: ASHLEY, B. M. The Way toward Wisdom, 2006. (Especialmente, as pp. 158163). Parte da discussão de Ashely em 2006 é retomada de um texto anterior, ver: ASHLEY, 1991, p. 1-15. No texto mencionado, Ashley não só critica outros tomistas, mas também expõe o que ele julga ser as oito principais teses sustentadas pela River Forest. Dentre estas, a terceira é justamente aquela que afirma que a filosofia natural prova a existência divina, (cf. ASHLEY, 1991, p. 4). Dewan em 1997 escreve um artigo no intuito de criticar esta terceira tese da River Forest, ver: DEWAN, L. St. Thomas, Physics, and the Principle Metaphysics. The Thomist, 1997, p. 549-66. ASHLEY, The Validity of Metaphysics: the Need for a Solidly Grounded Metaphysics, 1999 volta a discorrer sobre a temática. Ademais, no artigo referido Ashley anexa uma discussão designada como "Addendum". Seu objetivo é responder passo a passo as críticas de Dewan. Ainda tratando do debate, em 1994, Kondoleon escreve um artigo no intuito de criticar Knasas; ver: KONDOLEON, T. J. The Start of Metaphysics. The Thomist, 1994, p. 121-130. Em resposta, Knasas escreve outro artigo, ver: KNASAS, Thomistic Existentialism and the Proofs ex Motu at Contra Gentiles I, C. 13. The Thomist, 1995, p. 591-615. Em 1998 Kondoleon responde a Knasas com outro texto: KONDOLEON, T. J. The Argument from Motion and the Argument for Angels: A Reply to John F. X. Knasas. The Thomist,1998, p. 269-290.

16 Sobre a noção de força universal cósmica em Tomás, ver meu estudo: SANTOS, E. B. Os sentidos de theologia physica para os antiqui: Tomás de Aquino, leitor de Agostinho. Princípios, Natal 2017a, p. 9-41.

${ }^{17} \mathrm{O}$ texto latino da Physica II, 1 e sua respectiva tradução para o português, bem como uma análise introdutória da leitura de Tomás, encontram-se em SANTOS, E. B. A locomoção natural dos elementos: Tomás de Aquino, crítico de Aristóteles latino. Analytica, 2014, p. 123-151.

${ }^{18}$ Embora não empregue os termos "corpo celeste" e "motor separado", a terminologia empregada, assim como as ideias presente no Comentário de Filopono de Alexandria (490-570 d.C) ao Capítulo 1 do livro II da Física de Aristóteles (escrito por volta de 517) tornam o texto de Filopono (PHILOPONUS, 1887) um antecedente filosófico imediato do Comentário de Tomás (THOMAS AQUINAS, 1884) à mesma passagem aristotélica. Com efeito, além de recepcionar a definição aristotélica de natureza, Filopono também apresenta sua própria defi-

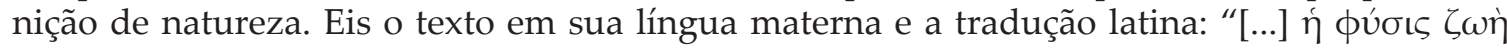


considera que Aristóteles estabelece sua definição clássica de natureza, ao que parece, se referindo exclusivamente à região sublunar, uma vez que não há sequer vestígios de discussões sobre a noção de céu na Physica II, 1. O procedimento de Tomás indica não somente certo sentido do verbo "comentar", mas também as preocupações cosmológicas emergentes na ordem do dia dos acadêmicos do século XIII, sobretudo quanto às discussões sobre o sentido filosófico da noção de criação e a subsequente unificação metafísica do cosmo. Com efeito, diferentemente de Aristóteles que não inclui os corpos celestes na definição de natureza, os corpos celestes, segundo Tomás, devem ser incluídos na definição de natureza porque eles são naturais do mesmo modo que se diz que os outros constituintes do cosmo são naturais, como os elementos. ${ }^{19}$

A inclusão dos corpos celestes na definição de natureza, em si mesma, não toca no problema da relação entre a filosofia natural e a imaterialidade. O problema aparece quando Tomás aborda a locomoção celeste:

[...] Este princípio, enquanto possui a potência natural para tal forma e movimento faz com que o movimento seja natural. A produção das coisas artificiais não é natural, pois mesmo estando presente o princípio material, não tem a potência natural para tal forma. Assim também o movimento local dos corpos celestes é natural, embora provenha de um motor separado, pois há no corpo celeste uma potência natural para tal movimento. ${ }^{20}$

Como parece óbvio, o In Physicorum é um texto de filosofia natural, ao menos é assim que entende o próprio Tomás. ${ }^{21}$ Nessa medida, a filosofia

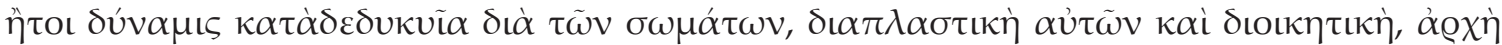

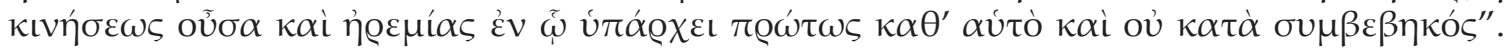
(PHILOPONUS, In Aristotelis physicorum libros tres priores Commentaria,1887, 197.33-198.2. "Natura est quaedam vita sive vis quae per corpora diffunditur, eorum formatrix et gubernatrix, principium motus et quietis in eo cui inest per se primo et non secundum accidens". (PHILOPONUS, Aristotelis Physicorum libri quatuor, 1558, p. 67, col. b, linhas 11-14). Como

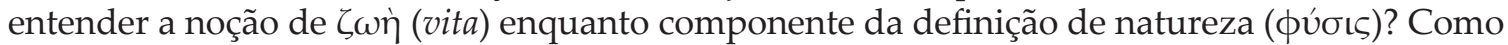
mostrei em meu primeiro estudo sobre Filopono, (cf. SANTOS, 2017b, p. 125-151), parece que a noção de vida presente no Comentário de Filopono ao capítulo citado necessariamente evoca as noções de alma e imaterialidade. Se assim for, Filopono, quase oito séculos antes de Tomás, aponta a direção à qual Tomás deve se dirigir.

${ }^{19}$ Sobre a naturalidade e locomoção dos corpos celestes em Tomás, ver: SANTOS, 2015, p. 95-124, p. 95-124.

${ }^{20}$ THOMAS AQUINAS, 1884: “[...] Quod quidem principium, inquantum habet potentiam naturalem ad talem formam et motum, facit esse motum naturalem. Et propter hoc factiones rerum artificialium non sunt naturales: quia licet principium materiale sit in eo quod fit, non tamen habet potentiam naturalem ad talem formam. Et sic etiam motus localis corporum caelestium est naturalis, licet sit a motore separato, inquantum in ipso corpore caeli est potentia naturalis ad talem motum".

${ }^{21}$ Algumas reflexões sobre a recepção na obra de Tomás do conceito de filosofia natural não somente no sentido aristotélico, mas também no sentido dos pré-socráticos, especialmente com relação a Anaximandro e a Empédocles, podem ser encontradas em SANTOS, E. B. A cosmologia e cosmografia de Anaximandro no In de Caelo de Tomás de Aquino. Kriterion, 2018 (no prelo); IDEM. Vestígios da Cosmologia de Empédocles em fontes latinas dos séculos XII-XIII, Dissertatio, 2016. Tomás também dialoga com Tales, ver: SANTOS, 2017a, p. 11-15. 
natural referencia o motor separado, este que, no contexto da definição de natureza, não é um motor natural, pois é imaterial, o que pode ser confirmado pelo caracterizador "intelectual" atribuído por Tomás ao princípio ativo da locomoção celeste no In DCM I, 3. n. 4:

[...] é preciso dizer que o princípio ativo do movimento dos corpos celestes é uma substância intelectual; porém, o princípio passivo é a natureza desse corpo, pela qual o corpo é capaz naturalmente de ser movido com tal movimento. ${ }^{22}$

Ademais, nota-se que além do In Physicorum, o In DCM também se refere ao motor separado, ou seja, o motor não-natural. Tal referência, entretanto, encontra-se sempre vinculada com o quesito sobre a locomoção celeste, o que pode implicar que não compete à filosofia natural abordar as questões sobre a natureza e existência do motor separado.

Na hipótese de a filosofia natural não abordar as questões sobre a natureza e existência do motor separado, é preciso ainda saber se a determinação de tais questões por outra ciência interessa a filosofia natural ou de algum modo exerce influência sobre suas investigações. Aqui, a meu ver, repousa uma das maiores diferenças entre Tomás e Aristóteles, pois para este, a metafísica só é instituída depois da filosofia natural, enquanto que, para aquele, a metafísica precede à filosofia natural e em várias ocasiões a regula.

\section{A filosofia natural aristotélica}

No intuito de enfatizar a importante diferença entre a filosofia natural aristotélica e a filosofia natural de Tomás, é preciso mencionar um dos estudos pioneiros que buscou a diferença entre Tomás e Aristóteles no contexto da metafísica. O maior objetivo da pesquisa de Joseph Owens (1908-2005) é mostrar a originalidade da metafísica do esse de Tomás. Desde sua tese de doutorado, Owens mostra que tal metafísica não consta na filosofia de Aristóteles, ${ }^{23}$ mas que ela é introduzida paulatinamente pelos pensadores cristãos, cujo ápice é Tomás. Dentre os tópicos investigados por Owens ao longo de sua pesquisa, a relação entre a filosofia natural e a metafísica possui certo destaque. Tal tópico é tratado por Owens numa série de artigos publicados entre 1952-1993. ${ }^{24}$

\footnotetext{
${ }^{22}$ THOMAS AQUINAS, 1886, I, 3, n.4: “[...] igitur dicendum est quod principium activum motus caelestium corporum est intellectiualis substantia: principium autem passivum est natura illius corporis, secundum quam natum est tali motu moveri".

${ }^{23}$ Cf. OWENS, J. The Doctrine of Being in the Aristotelian 'Methaphysics': A Study in the Greek Background of Mediaeval Thought, 1963.

${ }^{24}$ Dentre eles, enfatizo os seguintes: OWENS, J. "The Conclusion of the Prima Via" (1952/53);

"Aquinas and the Proof from the 'Physics'" (1966); "The Starting Point of the Prima Via" (1967);

"Actuality in the Prima Via of St. Thomas" (1967); "Immobility and Existence for Aquinas"
} 
Ao tratar sobre a relação entre a filosofia natural e a metafísica em Tomás, Owens centra-se nas provas da existência de Deus formuladas pelo Aquinata. Voltando-se à prima via (ST, Ia, q. 2, a. 3, resp.) e, no intuito de diferenciar o tratamento próprio de Tomás da fonte da qual ele tomaria emprestado a estrutura externa da prova, ou seja, a Física (VII-VIII) ${ }^{25}$ e a Metafísica (XII) de Aristóteles, Owens escreve:

A estrutura externa da prima via é obviamente tomada por Sto. Tomás de Aristóteles. Olhando por essa luz, o argumento tem sua fonte na Física e na Metafísica. No entanto, na Física a prova do movimento não parece alcançar nada além da alma celeste. Na Metafísica, a demonstração alcança uma pluralidade de substâncias separadas, cada uma das quais, embora seja ato sem mistura de potência é, não obstante, uma entidade finita. Em nenhum dos casos, o resultado da prova se assemelha ao Deus cristão. Todavia, o motor imóvel alcançado pelo procedimento de Aristóteles é dito por Sto. Tomás, sem qualquer comentário ou esclarecimento, ser o Deus sobre quem ele está tratando como um teólogo cristão. Como isso é possível? Certamente algo que é uma alma celeste ou uma pluralidade de entidades separadas finitas dificilmente é aquilo que os cristãos veem como sendo o Deus da revelação das Escrituras, o Deus que tinha se declarado a Si mesmo a Moisés nos termos do Exxodo: 'Eu sou o que Eu sou'. ${ }^{26}$

Ao comparar a prima via com a fonte que lhe confere a estrutura externa, Owens é bastante enfático: Aristóteles na Física (VII-VIII) não tem o objetivo e não direciona sua argumentação em vista de concluir sustentando a existência de algo que não seja natural, logo, que excede ao escopo da filosofia natural. O limite visado pela Física é a alma da última esfera. Quanto à Metafísica (XII), o cume para o qual ela aponta são as substâncias separadas, as quais, a despeito de serem puro ato, são finitas, portanto, não se equiparam à noção de Deus que as Escrituras revelam como o Ser (o Existente). Nessa medida, haveria uma diferença singular entre o escopo de Aristóteles na Física e na Metafísica e a revelação das Escrituras. A esse respeito, Owens questiona o procedimento de Tomás que, sem qualquer ressalva, simplesmente concluiria que o motor imóvel da Física, a alma da última esfera, ou qualquer um dos motores imóveis da Metafísica, uma das substâncias separadas, é o Deus revelado pelas Escrituras.

Tomás procede desse modo, responde Owens, porque ele radicaliza e transforma pela metafísica do esse os argumentos de Aristóteles restritos

(1968); "Judgment and Truth in Aquinas" (1970); "Aquinas as Aristotelian Commentator" (1974); "Aquinas on Knowing Existence" (1976); "Aristotle and Aquinas" (1993). Com exceção dos artigos OWENS, J. Aquinas and the Proof from the 'Physics'. Mediaeval Studies, v. 28, p. 119-150, 1966, e "Aristotle and Aquinas". In: KRETZMANN, N; STUMP, E. S (eds.). The Cambridge Companion to Aquinas. New York: Cambridge University Press, 1993. p. 38-59, os demais artigos foram reunidos e publicados na coletânea: OWENS, J. St. Thomas Aquinas on the Existence of God: collected papers of Joseph Owens, 1980.

${ }^{25}$ Owens usa a edição moderna da Física de Aristóteles. Nesse sentido, empregarei "Physica" para a edição latina e "Física" para a edição moderna.

${ }^{26}$ OWENS, 1980, p. 142. 
à investigação da forma. O ponto central que evidencia a radicalidade da nova perspectiva encontra-se na diferença entre a conclusão do argumento do movimento (Física VII-VIII; Metafísica XII) e a conclusão da prima via. Conforme já mencionado, nos textos referidos, Aristóteles não concebe algo além da forma, seja no domínio da filosofia natural seja da metafísica. O primeiro motor, portanto, no domínio da filosofia natural e da metafísica, não é uma entidade privilegiada dentre as demais. Tomás, por seu turno, ao empregar o argumento do movimento de Aristóteles na prima via, transforma esse argumento numa perspectiva existencial: é, pois, uma metafísica do movimento. ${ }^{27} \mathrm{~A}$ conclusão de Tomás aponta não para a forma, mas para o existente subsistente por si, o Ser. Ademais, segundo Owens, mesmo o argumento da Física que conclui estabelecendo a necessidade da eternidade do movimento é visto por Tomás de outro modo, a saber: o que é importante em tal argumento não é a eternidade do movimento por ela mesma, mas a condição de tal eternidade, qual seja, a origem do ser do móvel, a divindade. ${ }^{28}$

Pelo exposto nota-se que Aristóteles procede, mesmo no domínio da metafísica, como um filósofo da natureza. Tomás, por sua vez, no domínio da filosofia natural, às vezes é um metafísico. No intuito de entender esta relação complexa, é preciso compreender previamente os termos que compõem o argumento do movimento na Física, pela leitura de Owens. O argumento do movimento na Física possui as seguintes características: (i) ele pressupõe, baseado na sensação, que algumas coisas estão em movimento; (ii) postula-se inicialmente a proposição segundo a qual "tudo o que é movido, é movido por outro" e, posteriormente, se alcança esta outra proposição: "na mudança não se pode proceder ao infinito na série de motores".$^{29}$ A primeira proposição pode ser aplicada num contexto específico ou geral. Em ambos os casos, o movido é dividido em partes, a potência, que depende de outrem, e o ato, este que é per se. No primeiro caso, o termo "movido" tem como referência certa entidade numericamente una, um todo constituído de partes distintas, a segunda e a per se. Nesse caso, o todo é movido na medida em que a parte per se, o ato, atualiza a segunda parte, a potência. Disso decorre que na proposição "tudo o que é movido,

\footnotetext{
27 "A primeira das duas proposições [de Tomás na prima via] resulta de um exame metafísico do movimento visto nas coisas sensíveis". (OWENS, 1980, p. 144).

28 " [...] o que parece primeiramente interessar a Sto. Tomás neste argumento [da eternidade do movimento] é como a coisa móvel originariamente adquire seu esse, se a partir da eternidade ou não, não podendo ser pelo modo do movimento. O movimento, no mundo, mesmo sendo eterno, não pode, em última instância, ser produzido através do movimento. A natureza essencialmente imperfeita do movimento, aparece aqui, como no comentário ao livro VII [da Física], posto em evidência. O movimento requer algo além do movimento para explicar sua presença. Ademais, a eternidade do movimento, que é a base estabelecida pelo Estagirita para sua demonstração, é considerada por Tomás como irrelevante à prova. Se o movimento é eterno ou não, seu esse precisa ser explicado por um tipo de emanação da causa de todo o esse". (OWENS, 1980, p. 148).

${ }^{29}$ Cf. OWENS, 1980, p. 145-146.
} 
é movido por outro", o termo "movido" denota, numa primeira instância, a potência e, numa segunda instância, o todo. Já o termo "outro", por sua vez, denota a parte per se na medida em que diz respeito ao automovente. No que tange ao contexto geral, a referência diz respeito à relação entre entidades distintas. Nesse caso, cada uma é entendida como constituída das partes segunda e per se. Semelhante ao primeiro caso, apenas com a ressalva de que se trata de entidades ontologicamente distintas, uma dada entidade " $x$ " é motor de uma dada entidade " $y$ ".

Pela análise das partes que constituem o motor e o movido, Aristóteles teria alcançado o primeiro motor:

Finalmente, o primeiro motor não tem magnitude e está localizado na circunferência do universo onde o movimento é mais rápido. Este raciocínio, evidentemente, não conduz a nada além da alma do céu mais externo. A partir da eternidade do movimento, Aristóteles tinha mostrado por indução que, se está sendo movido, está sendo movido por outro. Mas, numa série de coisas que estão sendo movidas, deve haver um primeiro movente em virtude do qual os outros conferem movimento. Este primeiro movente não está sendo movido por outrem, e assim, precisa ser automovente; e num automovente, o movimento é causado por uma parte que é imóvel, como nas coisas animadas. A contínua eternidade do movimento, entretanto, só pode ser explicada por uma alma celeste que é imóvel per se e per accidens; e a única razão pela qual o movente primeiro deve ser imóvel, per se e per accidens, é esta continuidade eterna do movimento. Uma vez que a causalidade eficiente é explicada, no limite, pela forma como ato, nada é requerido além dessa ordem de causa. Cada forma, para Aristóteles, 'energiza-se' de sua própria natureza, quando nada impede. A alma do primeiro céu, nessa medida, é totalmente suficiente para explicar o primeiro movimento dos céus como causa eficiente. Na linha da causalidade eficiente, o argumento é fechado. Ele não deixa caminho aberto para discutir posteriormente qualquer eficiência de movimento. ${ }^{30}$

Owens nega que haja um tratamento da noção de existência na Física de Aristóteles. Isso significa que a conclusão do argumento do movimento não se refere à imaterialidade. Ademais, ele também nega que exista uma espécie de complementaridade entre a Física e a Metafísica no que tange à causa eficiente, ou seja, que a Física descobriria a causa eficiente que a Metafísica aprofundaria. ${ }^{31}$ A Física cumpre seu propósito, qual seja, explicar, no contexto absolutamente restrito da natureza, o movimento. O objetivo de Aristóteles, portanto, é tão somente sustentar que o movido requer outro que deve ser entendido como primeiro motor, pois do contrário a noção de movimento não possuiria explicação filosófica, donde a necessidade de se estabelecer a proposição negativa sobre a série infinita de motores.

${ }^{30}$ OWENS, 1980, p. 150-151.

31 “Elas eram um número limitado de formas separadas, cada uma confinada a sua própria atualidade distinta. Não havia, portanto, passagem de objetos materiais finitos às formas imateriais finitas". (OWENS, 1980, p. 209). 
Digno de nota ainda é o fato de que Aristóteles não antecipa considerações metafísicas no que toca à natureza de um primeiro motor. Owens é bastante enfático nesse quesito: o primeiro motor não é causa eficiente de existência, nem mesmo mediante o movimento. ${ }^{32}$ Compreendido como a anima (alma) da última esfera, o primeiro motor é causa eficiente de movimento no sentido de atualização de potências no móvel.$^{33}$ É, pois, uma entidade cósmica, e mesmo, na concepção grega de cosmo, ${ }^{34}$ uma entidade natural, tal como se diz que a alma de qualquer animado é natural.

Ao se deparar com os argumentos do movimento e da eternidade do movimento, Tomás os transforma substancialmente, pois os lê numa perspectiva da metafísica do esse. Tal perspectiva, segundo Owens, não está presente apenas no In Physicorum, mas também e, sobretudo, na prima via cuja conclusão entende a existência divina num sentido original concebido por Tomás, ou seja, mediante os termos ser e perfeição. Nessa medida, Tomás lê a noção de movimento na Física de Aristóteles pela negação da perfeição divina. Isso significa que o termo movido denota imperfeição na natureza do movido. O movimento, nesse contexto, não só é uma via para a perfeição, mas também requer, por parte do movido, que no motor preexista em ato a perfeição para a qual o movido é dirigido. A noção de ato, nesse contexto, não apenas tem como referência a noção de forma, mas também a noção de existência..$^{35}$ A conclusão da prima via, portanto, evidencia que o primeiro motor, não no sentido de Aristóteles, mas agora concebido por Tomás, é o existente (o Ser), nomeado por "todos" como "Deus".

Do exposto, segue-se que, mesmo fazendo referência à noção de movimento na prima via, Tomás não aceita que a filosofia natural prove a existência divina. Nesse sentido, no que tange à Física de Aristóteles, Tomás tem plena consciência de que seu escopo não ultrapassa a natureza e, que, por conseguinte, o motor imóvel, para o Estagirita, em si mesmo, é a alma da última esfera, uma entidade cósmica. No intuito de substituir o argumento da Física estabelecido por Aristóteles pelo argumento da metafísica, Tomás

\footnotetext{
32 “O problema de necessitar o mundo de um criador não se coloca [para Aristóteles], e uma causa eficiente é explicada em termos de origem de movimento em vez de doação de existência". (OWENS, 1993, p. 45)

33 "A natureza do primeiro movente alcançado pelo raciocínio aristotélico não é determinada. É deixada vagamente como o 'primeiro motor'. Mesmo a conclusão óbvia segundo a qual ele deve ser imóvel não é explicitada. O que está sendo movido, está sendo movido por algo, e uma série de motores que estão sendo movidos não pode se estender ao infinito. A única conclusão estabelecida pelo Estagirita das duas proposições é que deve haver um primeiro motor, não como causa final, mas como aquilo a partir do que o início do movimento procede". (OWENS, 1980, p. 146-147).

${ }^{34}$ Sobre a concepção grega do cosmo, ver: OWENS, 1993, p. 40-42.

35 "Para Aristóteles, ser atualizado significa adquirir forma. Para Tomás, significa ser trazido à existência, uma vez que, para ele, a existência é a atualidade de cada forma da natureza". (OWENS, 1980, p. 134). "No argumento tomista, portanto, o movimento não é compreendido como restrito ao processo pelo qual a matéria adquire forma". (OWENS, 1980, p. 222). "Para o Estagirita a fonte do ser é a forma; para Sto. Tomás é o ato de existir". (OWENS, 1980, p. 167).
} 
exclui deliberadamente duas características naturais do argumento de Aristóteles, a saber: a eternidade do movimento e a animação dos céus. ${ }^{36}$

O ponto preciso da discussão sobre os argumentos do movimento e da eternidade do movimento que interessa aqui consiste na resposta da seguinte questão: qual a natureza do motor imóvel ao qual a conclusão de tais argumentos diz respeito? No tratamento de Aristóteles, segundo a leitura de Owens, o motor imóvel na própria terminologia desse intérprete, é "[...] uma alma imanente na esfera", entendida como "[...] a forma de algo material" ${ }^{37} \mathrm{O}$ motor imóvel alcançado pela filosofia natural aristotélica, portanto, não pode ser separado da matéria, mesmo porque, como é a causa eficiente primeira do primeiro movimento na natureza, realizado pela última esfera, que é o primeiro motor movido (mesmo sendo automovente), ele não poderia ser separado da matéria. Por conseguinte, mesmo que haja algum sentido em dizer que o primeiro motor imóvel da Física é "imaterial", embora Owens insista em sua naturalidade, ele não é separado da matéria. Ademais, não há conflito entre a Física e a Metafísica, conforme Owens, porque na Metafísica, os motores imateriais (finitos) são tão somente causas finais do movimento, e o que a Física demonstra é a primeira causa eficiente do movimento. O primeiro motor aristotélico, por mais obscuro que seja, é parte do cosmo. Nessa perspectiva, ele é natural porque pertence ao escopo da filosofia natural. Portanto:

[...] a metafísica pressupõe a filosofia natural. Para Aristóteles, a metafísica requer o argumento da Física no intuito de alcançar as substâncias separadas. Para ele, nesse sentido, a filosofia natural é o único caminho para a metafísica disponível ao intelecto humano. Para ele, não se pode alcançar a ordem supra-sensível, exceto por meio da filosofia natural. Mas a extensão para o supra-sensível do processo argumentativo, iniciado na filosofia natural, ocorre apenas na metafísica. No interior da filosofia natural em si o argumento do movimento, como apresentado na Física, mostra totalmente a limitação incisivamente notada por Suarez, segundo o qual nela não se alcança uma substância imaterial, muito menos uma substância incriada. ${ }^{38}$

\footnotetext{
36 "Não existe a questão de ser ele uma alma celeste [i.e., "Deus" na conclusão da prima via]. Na segunda via do movimento [SCG I, 13], Sto. Tomás seguindo as etapas do argumento tal como é encontrado no oitavo livro da Física, admite que ele alcança apenas uma alma celeste, e então seguindo Aristóteles na Metafísica alcança um motor inteiramente separado. Em nenhum dos casos, portanto, para Sto. Tomás, significa que Deus é alcançado por uma argumentação puramente física ou que a prova do movimento pertence à filosofia natural. No que toca ao argumento na Física, Sto. Tomás tem o cuidado de deixar claro que, se os dois fundamentos aristotélicos, da eternidade do mundo e da animação dos céus, são omitidos, então o argumento conclui diretamente para Deus. Nem é uma atitude de não se importar no momento [do argumento] se o motor imóvel é uma alma do mundo ou uma alma celeste tal como encontra-se na Summa. O texto encara o argumento como alcançando um motor imóvel que todos compreendem ser Deus. Não há nenhum indício de qualquer indiferença para com a natureza do motor alcançado". (OWENS, 1980, p. 161).

${ }^{37}$ OWENS, 1966, p. 120.

${ }^{38}$ OWENS, 1966, p. 126-127.
} 
Quero destacar duas afirmações precisas no que se refere à relação entre a filosofia natural e a metafísica em Aristóteles, na leitura de Owens, quais sejam: (i) a metafísica só é instituída depois da filosofia natural; (ii) a imaterialidade só é alcançada depois do tratamento sobre o movimento. Pela primeira afirmação é possível entender que a ordem do ensino é a própria ordem de instituição da ciência. Isso significa que quando da instituição da filosofia natural não há realmente qualquer conhecimento sobre a imaterialidade. A razão disso, a meu ver, se dá na completa ausência em Aristóteles do que Owens denominou anteriormente de problema existencial tal como encontra-se em Tomás. A necessidade da precedência na instituição da metafísica com relação à filosofia natural decorre, no caso de Tomás, de sua concepção de existência. No que se refere à segunda afirmação, por sua vez, é verdade que o tratamento do movimento por Aristóteles na filosofia natural conduz à imaterialidade, mas ele não adentra neste domínio. O ponto central que mostra o estancamento do tratamento natural, dando, por conseguinte, a oportunidade à instituição da metafísica, é a noção de causalidade aí envolvida. A investigação do movimento na filosofia natural de Aristóteles, segundo Owens, em hipótese alguma aborda a causalidade eficiente no âmbito do imaterial tendo o cosmo como referência. Esse tópico é inexistente, para o próprio Estagirita. Portanto, não há em Aristóteles uma metafisica da causalidade eficiente. A causa eficiente é, na sua perspectiva, exclusividade da filosofia natural.

\section{Causa eficiente e imaterialidade na filosofia natural}

A diferença entre Aristóteles e Tomás no quesito da causalidade eficiente na filosofia natural é notória. $\mathrm{O}$ imaterial, no domínio do cosmo, não pode ser causa eficiente de movimento, para o mestre do Liceu. ${ }^{39}$ Para Tomás, por outro lado, a divindade ou a inteligência, no domínio do cosmo, necessariamente é causa eficiente de movimento. Tomás, por conseguinte, não entende que a noção de um primeiro motor possa designar algo natural, mas deve designar a entidade imaterial e, mesmo transcendente e infinita ${ }^{40}$ Nesse último caso, da divindade se diz que causa movimento (influit motum) no sentido de conferir o primeiro impulso de um corpo e, no caso de ser um corpo celeste, tal impulso equivale a uma força de valor perene, pois nem aumenta nem diminui. A divindade, portanto, para Tomás, é causa eficiente de ser e causa eficiente de movimento.

\footnotetext{
39 “No quadro aristotélico, por conseguinte, o primeiro motor da Física VII exerce um tipo de causalidade que ele não poderia exercer caso fosse uma forma imaterial". (OWENS, 1966, p. 123).

${ }^{40}$ A tese tomista da transcendentalidade divina tem em Aertsen seu grande expoente, cf. AERTSEN, 1996. Ver também: AERTSEN, 2012.
} 
No que se refere à existência divina, entretanto, as últimas linhas do In Physicorum VIII, 23, n. 9, são enigmáticas, pois aí, aparentemente, é afirmado que a filosofia natural aristotélica tem por conclusão a afirmação da existência divina. ${ }^{41}$ Entretanto, é possível e razoável sustentar que no In Physicorum VIII, 23, n. 9, Tomás não afirme que a filosofia natural prova a existência divina. Para tanto, é preciso se ater, por um lado, à origem do movimento que decorre da criação e, por outro lado, à terminologia empregada por Tomás.

A despeito da introdução de considerações metafísicas no In Physicorum VIII, 23, n. 9, Tomás evidencia que a discussão sobre a noção de um primeiro motor pode ser encarada no âmbito da filosofia natural e da metafísica, numa espécie de discussão interdisciplinar decorrente do vínculo íntimo e indissociável entre as noções de movimento e existência. Nesse sentido, quando se considera o movimento numa perspectiva do cosmo, a existência é pressuposta. Aliás, para Tomás, o tratamento do movimento cósmico, que é seu aspecto mais aprofundado, pois diz respeito à locomoção natural dos elementos e dos astros tomados em conjunto, jamais prescinde do tratamento sobre a existência, pois a origem radical do movimento cósmico, não seu início temporal, não tem a natureza como princípio, mas o criador. ${ }^{42}$ Assim sendo, no In Physicorum VIII, 23, n. 9, pode-se focar na filosofia natural em sentido aristotélico, cujo alcance é a alma da última esfera (alma esta inexistente, para o próprio Tomás), ou pode-se focar na metafísica, cujo alcance é o criador.

Ocorre, porém, que o duplo aspecto da divindade mencionado deverá permanecer sempre como um tópico de difícil compreensão, ou seja, a eficiência divina no âmbito do movimento e da existência. A dubiedade torna-se ainda mais marcante pela constatação que aponta para a dificílima demarcação semântica, na hipótese de ser possível, entre a noção de natureza entendida como a causa do movimento natural do conjunto formado pelos elementos e pelos astros e a noção de divindade, também entendida como a causa do movimento cósmico. Se a referência é o ente natural, mais precisamente, o elemento ou astro alocado em sua esfera logo após a geração (ou criação), como diferenciar a causa do ser do ente natural e a causa do movimento deste mesmo ente natural em sua esfera? Conferir o ser ao ente natural na ocasião da geração (ou criação) parece que implica necessariamente em conferir a força centrípeta, centrífuga ou circular.

\footnotetext{
41 "Et sic terminat Philosophus considerationem communem de rebus naturalibus, in primo principio totius naturae, qui est super omnia Deus benedictus in saecula. Amen". (THOMAS AQUINAS, 1884, VIII, 23, n. 9).

${ }^{42}$ Sobre tal tópico, ver: SANTOS, 2017, p. 11-15.
} 
A via segura que Tomás poderia percorrer para, simultaneamente, evitar a questão mencionada e se manter no interior da tradicional filosofia natural aristotélica seria negar que a divindade é causa eficiente de movimento. Tomás, entretanto, escolhe sua própria via:

Ao terceiro, é preciso dizer que, na ciência natural não se trata (agitur) do primeiro motor como de seu sujeito ou de parte do sujeito, mas como do termo ao qual a ciência natural conduz. Ora, o termo não pertence à natureza da coisa da qual é termo, mas tem alguma relação para com esta coisa, assim como o termo da linha não é linha, mas tem para com ela alguma relação. Assim também o primeiro motor é de outra natureza que as coisas naturais; tem, no entanto, para com elas alguma relação, na medida em que lhes influi o movimento, e assim cai na consideração da ciência natural, quer dizer, não por si mesmo, mas na medida em que é motor. ${ }^{43}$

A filosofia natural de fato trata (agitur) do imaterial, mas ela não demonstra o imaterial. Aqui, a atenção na terminologia é fundamental, caso contrário qualquer tentativa de intepretação é totalmente arruinada porque tudo se reduz a sinonímia. Nessa medida, é preciso enfatizar que nem no SBDT, q. 5, a. 2, obj.3, nem no SBDT, q. 5, a. 2, ad3, Tomás emprega os termos técnicos para "demonstração/prova": ostendere, demonstratur, probatur. Assim sendo, agitur é sinônimo de traditur, e em contextos bastante precisos não serão sinônimos de ostendere, demonstratur, probatur. Nesse contexto, entendo que Tomás é muito cuidadoso com os termos latinos que denotam "demonstração/prova". Ele jamais empregaria levianamente estes termos, bem como se quisesse manifestar ao leitor a tecnicidade da "demonstração/ prova" empregaria um dos três termos mencionados, como faz inúmeras vezes ao longo da SCG e da ST.

A ênfase no sentido técnico de "demonstração/prova" pode ser observada, por exemplo, em dois fragmentos:

(I) "Sic ergo ratione demonstratur et fide tenetur quod omnia sint a Deo creata" ${ }^{44}$

(II) "Respondeo a quod creationem esse non tantum fides tenet, sed etiam ratio demonstrat". ${ }^{45}$

\footnotetext{
${ }^{43}$ THOMAS AQUINAS, 1992, q.5 a.2 ad3 (Trad. de Carlos A. R. do Nascimento. Aqui com modificações): "Ad tertium dicendum quod de primo motore non agitur in scientia naturali tamquam de subiecto vel de parte subiecti, sed tamquam de termino ad quem scientia naturalis perducit. Terminus autem non est de natura rei, cuius est terminus, sed habet aliquam habitudinem ad rem illam, sicut terminus lineae non est linea, sed habet ad eam aliquam habitudinem, ita etiam et primus motor est alterius naturae a rebus naturalibus, habet tamen ad eas aliquam habitudinem, in quantum influit eis motum, et sic cadit in consideratione naturalis, scilicet non secundum ipsum, sed in quantum est motor".

${ }^{44}$ THOMAS AQUINAS, 1925, q.3 a.5, resp.“Portanto, a razão demonstra e a fé sustenta que todas as coisas foram criadas por Deus".

${ }^{45}$ THOMAS AQUINAS, 1929, II d.1 q.1 a.1 resp.“Respondo que não somente a fé sustenta a criação, mas a razão também a demonstra".
} 
Nestes fragmentos, é patente que Tomás deseja diferenciar os termos tenetur/tenet e demonstratur/demonstrat. Os primeiros têm como referência uma disposição "subjetiva", um "assentimento", pois estão vinculados à fide/ fides. Os segundos, por sua vez, possuem como referência a objetividade (ratione/ratio), ou seja, a conclusão de um argumento válido cujas premissas são necessariamente verdadeiras. Trocar um termo pelo outro no contexto em que são empregados seria desastroso. Ademais, a breve menção a estes fragmentos aqui visa tão somente acenar para a tecnicidade concebida por Tomás para os termos ostendere, demonstratur, probatur e, que, o não uso de tais termos deve ser cuidadosamente respeitado e analisado. Conforme apontado, Tomás não emprega estes termos no SBDT, q. 5, a. 2, obj.3, e no SBDT, q. 5, a. 2, ad3. Eu entendo que esta ausência é totalmente coerente com o pensamento de Tomás e que, portanto, o tratamento da filosofia natural sobre o primeiro motor não diz respeito à demonstração (prova).

A noção de relação no SBDT, q. 5, a. 2, ad3, é articulada com a expressão "influir movimento" (influit motum). O primeiro motor influi o movimento no interior (ou no mais íntimo) da coisa estabelecendo relação (de providência) com ela. É, pois, a entidade transcendente. A relação afirmada se dá no domínio do esse e, para Tomás, só a divindade confere o esse, razão pela qual ao influit esse, a divindade influit motum. ${ }^{46}$

No que se refere à noção de divindade empregada por Tomás em discussões de filosofia natural, deve-se observar que a filosofia natural não trata da natureza da divindade. É por essa razão que Tomás prefere designar a divindade no domínio da filosofia natural como motor. Cumpre notar, entretanto, que o termo "motor" é por si mesmo complexo quando se trata de relacionar Tomás com outros filósofos, como no caso de Aristóteles, pois enquanto que para outros a referência, no âmbito do cosmo, pode ser um ente natural, para Tomás, necessariamente é a divindade. A seguinte passagem do In DCM III, 1, n. 4 evidencia a complexidade apontada:

[...] a maior parte da história natural (ou seja, da narração) diz respeito aos corpos. Diz a maior parte, porém, é preciso entender toda [a história natural]; emprega esse modo de se expressar devido à medida filosófica. Ou diz a maior parte porque na ciência natural se trata (traditur) também de algo sobre o primeiro motor e sobre a alma intelectiva. ${ }^{47}$

Qual o exato sentido de "traditur" referente ao primeiro motor e a alma intelectiva? Primeiro, deve-se observar que Tomás não toma como premissa a imaterialidade da alma intelectiva para inferir que o primeiro motor existe e que é imaterial (cf. ST, Ia, qq. 75-76). Ademais, o próprio Tomás afirma que a

${ }^{46}$ Cf. THOMAS AQUINAS, 1929, IV, d. 50, q. 1, a. 1, resp.

${ }^{47}$ THOMAS AQUINAS, 1886, III, 1 n.4: “[...] plurimum historiae (idest narrationis) naturalis est circa corpora. Per hoc autem quod dicit plurimam, inteiligit omnem; sed utitur hoc modo loquendi propter philosophicum temperamentum. Vel dicit plurimam, propter hoc quod in scientia naturali aliquid etiam traditur de primo motore et de anima intelectiva". 
consideração da alma em si mesma, ou seja, sem referência propriamente ao corpo, pertence ao teólogo (cf. ST, Ia, q. 75, prooemium), e noutro contexto, a saber: no In Physicorum II, 4, n. 10, §1 ele afirma que pertence ao filósofo primeiro; não compete ao filósofo natural, portanto, a demonstração.

As investigações sobre alma intelectiva e sobre o primeiro motor são distintas na base, pois abordam naturezas absolutamente distintas. Mesmo na hipótese de se encontrar Tomás afirmando que a filosofia natural demonstra a imaterialidade da alma intelectiva, a suposta demonstração não serviria de premissa para alcançar a imaterialidade do primeiro motor. Assim sendo, se traditur no que tange à alma intelectiva denota a demonstração de sua imaterialidade no In DCM III, 1, n. 4, ele não designará demonstração quanto ao primeiro motor.

Centrando-se no caso do termo traditur aplicado ao primeiro motor, uma vez que, para Tomás, ele não designa "demonstração", é necessário investigar seu sentido. Antes, porém, é preciso notar que na ST e na SCG Tomás identifica a expressão "primeiro motor" com a divindade (cf. ST, Ia, q. 2; SCG I, 13). Além disso, pela expressão influit motum, cujo sentido remonta à influit esse, o primeiro motor, no contexto do cosmo, em Tomás, só pode denotar a divindade, pois, como já observado, trata-se da origem radical do movimento cósmico, qual seja: a criação.

A filosofia natural enquanto ciência geral, embora não demonstre nenhuma tese referente à natureza e existência do primeiro motor (o criador), ela transmite (traditur) alguma informação sobre ele. Pelo que entendo, esta transmissão é uma autêntica tentativa de entender, na medida do possível, o influit motum, sem adentrar no influit esse (do domínio propriamente da metafísica), embora o filósofo natural tomista saiba de antemão que as expressões estão necessariamente vinculadas. Nesse sentido, toda a riqueza da expressão influit esse sempre está presente, mas o filósofo natural se concentra no influit motum.

Tomás no SBDT, q. 5, a. 2, ad3, não afirma que o "primus motor influit esse", como faz no contexto da metafísica, afirma, diferentemente, que o "motor primus [...] influit motum". Isso significa, então, que não somente como causa final a filosofia natural trata sobre o primeiro motor, mas também como causa eficiente de movimento. Em outras palavras, a divindade enquanto primeiro motor é considerada pela filosofia natural e pela metafísica. Pela filosofia natural como motor final e eficiente de movimento. Pela metafísica, por sua vez, como motor final de perfeição e de bondade, assim como causa formal e causa eficiente de existência, em suma, como criador (cf. ST, Ia, qq. 44-45).

A consideração sobre o primeiro motor como causa eficiente de movimento, empreendida pela filosofia natural, requer bastante atenção, pois Tomás não está afirmando qualquer resquício de ocasionalismo (cf. SCG III, 69). 
A concepção segundo a qual o primeiro motor influit motum diz respeito a dois contextos. O primeiro, o metafísico, refere-se à noção de conservação, ou seja, a manutenção da operação divina que confere as potências ativas e passivas das quais o movimento é consequência (cf). ${ }^{48}$ Não diz respeito à operação de criação porque nesta não há substrato prévio, conquanto a manutenção ocorre em algo que já possui existência. Quanto ao segundo, por seu turno, trata-se da compreensão da filosofia natural de que a divindade é o motor eficiente da locomoção natural da última esfera.

Cumpre observar que o próprio Tomás nega uma hipótese que poderia estar relacionada com a compreensão da filosofia natural sobre o primeiro motor (cf. SCG III, 68, 5§.). Nessa hipótese, o primeiro motor estaria vinculado à locomoção do primeiro céu, isto é, da última esfera e, embora a última esfera não seja o lugar para o primeiro motor, pois ele é imaterial, a aplicação de seu poder, no caso de ser dito motor eficiente, estaria restrito a este lugar. Antes, porém, de apresentar a reação de Tomás a esta hipótese, é conveniente mencionar, sucintamente, o modo pelo qual Tomás entende a causalidade eficiente dos entes imateriais, a alma humana e as inteligências separadas.

No homem, segundo Tomás, a alma enquanto forma e enquanto motor se identificam, diferindo apenas no âmbito conceitual (cf. DSC, a. 3, ad7). A alma humana, a despeito de sua imaterialidade, constitui o composto homem, razão pela qual tem sentido dizer que a alma está no corpo, unida a ele enquanto forma (cf. DSC, a. 2, resp.) e, além disso, governa-o enquanto motor (cf. DSC, a. 3, ad7). Trata-se, portanto, da relação de constituintes do composto. Como motor do corpo, a alma se move ao mover o corpo (cf. DSC, a. 4, ad7), pois é constituinte do composto homem. O movimento tem início no coração, este que, por sua vez, move as partes sutis do corpo, os espíritos (cf. DSC, a. 3, resp.). Nessa medida, a alma enquanto motor necessita da distinção entre as partes do corpo. Entretanto, há uma operação da alma, segundo Tomás, que ocorre independentemente dos órgãos corpóreos, a saber, a intelecção. Isso indica que o poder (virtus) da alma excede o corpo, razão pela qual, embora esteja na totalidade do corpo, mesmo sem ser extensa (non habet extensionem in materia), ela não se identifica com as diversas partes deste e, de certo modo, ultrapassa (excedit) os limites corpóreos (cf. DSC, a. 4, resp.).

A relação entre as inteligências separadas e os céus, na concepção de Tomás, difere da relação entre a alma e o corpo que constituem o homem, pois as inteligências e os céus são distintos ontologicamente, uma vez que não constituem um composto. Nesse sentido, a relação entre as inteligências e os céus não diz respeito à relação entre forma e matéria, mas entre motor, constituído de forma e ser, e movido, constituído de forma e

${ }^{48}$ Cf. THOMAS AQUINAS, 1929, II, dd. 12-18; IDEM, 1888, Ia, qq. 65-74. 
matéria. Não havendo relação de constituintes, tal como no homem, não se diz que as inteligências estão nos céus e que se movem por acidente. A este respeito, Tomás no DSC, a. 4, arg. 10, elabora uma objeção a sua concepção advinda da concepção de Aristóteles. Na objeção a noção de circunferência é tomada como denotando a esfera na qual o astro encontra-se em locomoção. O centro, por sua vez, denota o próprio eixo do astro. $\mathrm{Na}$ perspectiva aristotélica, o motor não estaria no astro propriamente, mas em alguma parte da esfera, notadamente no oriente dela, pois é por ele que o astro inicia seu percurso pelas constelações. Tomás de modo sutil reprova a afirmação aristotélica de que o motor do céu estaria em uma determinada parte da esfera: “O anjo é comparado ao corpo celeste que ele move não como forma, mas como motor; donde não é semelhante à alma, que é forma do todo e de qualquer parte". ${ }^{49}$ Enquanto motor, portanto, a inteligência (anjo) excede não a totalidade dos céus, pois ela não é transcendente, mas à esfera e ao astro que ela move, não estando restrito a uma determinada parte, ou seja, ao oriente da esfera, mesmo porque ela, por natureza, é mais nobre do que a alma humana, esta que, de certo modo, excede às partes do corpo.

Tomás ao tratar da hipótese segundo a qual a divindade seria o motor do primeiro céu, escreve:

Pelo exposto acima fica excluído o erro de alguns que dizem que Deus está em alguma determinada parte do mundo, ou seja, no primeiro céu e na parte do oriente [do céu], donde procede o princípio do movimento celeste. Pode-se, no entanto, aceitar essas afirmações se elas forem consideradas retamente, isto é, se não pensarmos que Deus está limitado a determinada parte do mundo, mas que o princípio dos movimentos de todos os corpos começa, segundo a ordem natural, em determinada parte, sendo Deus o movente..$^{50}$

A afirmação que Tomás refuta, qual seja, que a divindade estaria restrita no oriente do primeiro céu, limita a compreensão da noção de divindade no âmbito de sua natureza e de seu poder, pois, nesse caso, a divindade não seria compreendida como transcendente. É devido a sua compreensão da transcendentalidade divina, assunto este do domínio da metafísica, que Tomás repudia a afirmação segundo a qual a divindade estaria no oriente celeste. Entretanto, se não denotar que ela esteja limitada no oriente, há razoabilidade em afirmar que a divindade é o motor eficiente do movi-

\footnotetext{
49 THOMAS AQUINAS, 2000, a. 4, ad10: "Angelus comparatur ad corpus caeleste quod movet, non sicut forma, sed sicut motor; unde non est simile de ipso et de anima, quae est forma totius et cuiuslibet partis".

${ }^{50}$ THOMAS AQUINAS, 1934, III, 68, §5 (Trad. de Odilão Moura): “Per hoc autem excluditur error quorundam dicentium Deum in aliqua parte mundi determinata esse, puta in primo caelo et in parte orientis, unde est principium motus caeli. Quorum tamen dictum sustineri posset si sane accipiatur: ut scilicet non intelligamus Deum aliqua determinata mundi parte esse conclusum; sed quia omnium corporearum motionum principium, secundum naturae ordinem, ab aliqua determinata incipit parte, Deo movente" .
} 
mento da última esfera, uma afirmação pertencente ao filósofo natural que pressuporia o estabelecimento metafísico da transcendentalidade divina.

\section{Considerações finais}

A pronúncia da filosofia natural sobre a divindade enquanto motor da última esfera evidencia que a filosofia natural, segundo Tomás, mesmo que de modo breve, transmite alguma informação sobre a divindade, não só como causa final do movimento, mas também como causa eficiente de movimento. Excetuando as justificativas de caráter metafísico, pelo viés da filosofia natural a afirmação segundo a qual a divindade é motor eficiente de movimento se justifica também pela admissão tomista de que todo movimento é fundamentado em algo imóvel não somente enquanto fim, mas também como eficiente. Ao menos duas razões viabilizam a afirmação segundo a qual todo movimento se fundamenta em algo imóvel e eficiente. A primeira diz respeito às inteligências separadas que são causas eficientes da locomoção celeste, embora sejam imóveis (cf. SCG III, 23). A segunda, por sua vez, refere-se à perfeição da locomoção celeste, pois mesmo sendo contínua, nada acrescenta ou retira de sua natureza. Portanto, embora sejam móveis segundo o lugar, os corpos celestes são imutáveis segundo a natureza (cf. ST, Ia, q. 66, a. 2, resp.). Nessa medida, dentre os entes naturais, os corpos celestes se aproximam ao máximo da imobilidade:

Ademais, o primeiro princípio do movimento deve ser algo imóvel. Sendo assim, as coisas que mais se aproximam da imobilidade devem ser motoras de outras. Com efeito, os corpos celestes mais se aproximam da imobilidade do primeiro princípio do que os corpos inferiores, porque são movidos apenas com uma espécie de movimento, qual seja, o movimento local; entretanto, os outros corpos são movidos com todas as espécies de movimentos. Portanto, os corpos celestes são motores e regentes dos corpos inferiores. ${ }^{51}$

Embora a conclusão da passagem aponte para a eficiência e regência dos corpos celestes, a passagem completa também evidencia que a divindade é causa eficiente de movimento, o primum principium motus. A razão pela qual a divindade é o primum principium motus e, ademais, os corpos celestes são ditos eficientes, decorre da imobilidade. Porque é absolutamente imóvel que a divindade é maximamente eficiente. Semelhantemente, é porque se aproximam ao máximo da imobilidade divina, pois das espécies de movimento sofrem apenas uma, a local, que os corpos celestes são, dentre os

${ }^{51}$ THOMAS AQUINAS, SCG III, 82, §5: “Oportet primum principium motus esse aliquid immobile. Quae ergo magis accedunt ad immobilitatem, debent esse aliorum motiva. Corpora autem caelestia magis accedunt ad immobilitatem primi principii quam inferiora: quia non moventur nisi una specie motus, scilicet motu locali; alia vero corpora moventur omnibus speciebus motus. Corpora igitur caelestia sunt motiva et regitiva inferiorum corporum". 
entes naturais, os mais eficientes, e isso de tal modo que regem a região sublunar. Portanto, nota-se que a imobilidade dentre as causas superiores é, para Tomás, sinal de grau de eficiência.

Noutra passagem, a saber, na SCG III, 23, §12, Tomás também considera a afirmação da filosofia natural de que a divindade é o primeiro princípio do movimento do primeiro céu:

Por conseguinte, quanto à presente questão, é indiferente se o corpo celeste é movido por uma substância intelectual conjunta que lhe sirva de alma, ou por uma substância separada, ou se cada corpo celeste é movido por Deus; ou se nenhum o é imediatamente, mas mediante potências intelectuais criadas; ou se só o primeiro, imediatamente por Deus, e os demais mediante substâncias criadas. O importante é que se admita que o movimento celeste provém de uma substância intelectual. ${ }^{52}$

Antes da redação da SCG III, 23, §12, Tomás já havia mostrado que o cosmo é criado (SCG II, cc. 6; 15-17), incluindo as inteligências separadas (SCG II, cc. 50-54), razão pela qual mesmo que a locomoção celeste não provenha diretamente da divindade como primum principium motus, mas apenas como primum principium essendi, provém da inteligência separada, esta que, por sua vez, só existe por criação, donde decorre que o movimento celeste estará subordinado à vontade e ao poder divino. Das hipóteses apontadas por Tomás na SCG III, 23, 12§, estas duas "se cada corpo celeste é movido por Deus"; "se só o primeiro [corpo celeste é movido] imediatamente por Deus", são as que mais se harmonizam com SBDT, q. 5, a. 2, ad3, In DCM III, 1, n. 4, e com In Physicorum II, 1, n. 4, pois elas manifestam a razão pela qual a filosofia natural tem como referente também o imaterial no âmbito do cosmo e, ademais, transmite alguma informação sobre a divindade, qual seja, a divinitas é o primum principium motus da filosofia natural e não somente o primum principium essendi da metafísica.

\section{Referências}

AERTSEN, J. A. Nature and Creature: Thomas Aquinas's Way of Thought. Leiden: Brill, 1988.

. Medieval Philosophy \& the Transcendentals: the Case of Thomas Aquinas. Leiden: Brill, 1996.

. Medieval Philosophy as Transcendental Thought: From Philip the Chancellor (ca. 1225) to Francisco Suárez. Leiden-Boston: Brill, 2012.

\footnotetext{
52 THOMAS AQUINAS, 1934, III, 23, §12 (Trad. de Odilão Moura): “Non differt autem, quantum ad praesentem intentionem, utrum corpus caeleste moveatur a substantia intellectuali coniuncta, quae sit anima eius, vel a substantia separata; et utrum unumquodque corporum caelestium moveatur a Deo immediate, vel nullum, sed mediantibus substantiis intellectualibus creatis; aut primum tantum immediate a Deo, alia vero mediantibus substantiis creatis; dummodo habeatur quod motus caelestis est a substantia intellectuali".
} 
ASHLEY, B. M. The River Forest School and the Philosophy of Nature Today. In: LONG, R. J. (ed.). Philosophy and the God of Abraham: essays in memory of James A. Weisheipl. Toronto: Pontifical Institute of Mediaeval Studies, 1991. p. 1-15.

. The Validity of Metaphysics: the Need for a Solidly Grounded Metaphysics. (1999).

Disponível em: http://www2.nd.edu/Departments/Maritain/ti99/ashley. htm\#addendum. Acesso em 10 jan. 2017.

.The Way toward Wisdom: An Interdisciplinary and Intercultural Introduction to Metaphysics. Notre Dame, Indiana: University of Notre Dame Press, 2006.

BEAVERS, A. F. Motion, Mobility, and Method in Aristotle's "Physics": Comments on "Physics" 2.1.192b20-24. The Review of Metaphysics, v. 42, n. 2, p. 357-374, 1988.

CORNOLDI, G. M. The Physical System of St. Thomas. Tr. by Edward Heneage Dering. New York, Cincinnati \& Chicago: Benziger Bros, 1893.

DEWAN, L. St. Thomas, Physics, and the Principle Metaphysics. The Thomist, v. 61, p. 549-66, 1997.

ELDERS, L. J. La philosophie de la nature de Saint Thomas d'Aquin: philosophie générale de la nature, cosmologie, philosophie du vivant, anthropologie philosophique. Paris: Pierre Téqui, 1994.

St. Thomas Aquinas's Commentary on Aristotle's Physics. Review of Metaphysics, v. 66, n. 4, p. 713-748, 2013.

JOHNSON, M. F. St. Thomas's De trinitate, Q. 5, A. 2, ad 3: A Reply to John Knasas. The New Scholasticism, v. 63, p. 58-65, 1989.

Immateriality and the Domain of Thomistic Natural Philosophy. The Modern Schoolman, v. 67, p. 285-304, 1990.

Does Natural Philosophy Prove the Immaterial? A Rejoinder. American Catholic Philosophical Quarterly, v. 65, p. 97-105, 1991.

KNASAS, J. F. X. Ad Mentem Thomae Does Natural Philosophy Prove God? Proceedings of the American Catholic Philosophical Association, v. 61, p. 209-220, 1987.

Immateriality and Metaphysics. Angelicum, v. 65, p. 44-76, 1988.

. “Does Natural Philosophy Prove the Immaterial?": An Answer to Mark Johnson. American Catholic Philosophical Quarterly, v. 64, n. 2, p. 265-269, 1990.

. Materiality and Aquinas' Natural Philosophy. A Reply to Johnson. Modern Schoolman, v. 68, n. 3, p. 245-257, 1991.

. Thomistic Existentialism and the Proofs ex Motu at Contra Gentiles I, C.

13. The Thomist, v. 59, p. 591-615, 1995. Press, 2003.

Being and Some Twentieth-Century Thomists. New York: Fordham University

KONDOLEON, T. J. The Start of Metaphysics. The Thomist, v. 58, 1994, p. 121-130.

The Argument from Motion and the Argument for Angels: A Reply to John F. X. Knasas. The Thomist, v. 62, 1998, p. 269-290. 
LANG, H. S. Thomas Aquinas and the Problem of Nature in Physics II, 1. History of Philosophy Quarterly, v.13, n. 4, p. 411-432, 1996.

MCWILLIAMS, J. A. Physics and philosophy: a study of Saint Thomas' commentary on the eight books of Aristotle's Physics. Washington, D.C.: Catholic University of America, 1945.

OWENS, J. The Doctrine of Being in the Aristotelian 'Methaphysics': A Study in the Greek Background of Mediaeval Thought. Toronto: Pontifical Institute of Medieval Studies, 1963. 150, 1966.

. Aquinas and the Proof from the 'Physics'. Mediaeval Studies, v. 28, p. 119-

St. Thomas Aquinas on the Existence of God: collected papers of Joseph Owens. Albany: State Univ. of New York, 1980.

. Aristotle and Aquinas. In: KRETZMANN, N; STUMP, E. S (eds.). The Cambridge Companion to Aquinas. New York: Cambridge University Press, 1993. p. 38-59.

PHILOPONUS, IOANNES. Aristotelis Physicorum libri quatuor. Venice: Hieronymus Scotus, 1558;

. In Aristotelis physicorum libros tres priores Commentaria. Berlin: G. Reimeri, 1887.

SANTOS, E. B. A locomoção natural dos elementos: Tomás de Aquino, crítico de Aristóteles latino. Analytica, Rio de Janeiro, v. 18, p. 123-151, 2014.

. Causalidade e Natureza na Cosmologia de Tomás de Aquino. Philósophos, Goiânia, v. 20, n. 1, p. 95-124, 2015.

- Vestígios da Cosmologia de Empédocles em fontes latinas dos séculos XII-XIII. Dissertatio, Pelotas, v. 44, p.131-150, 2016.

. Os sentidos de theologia physica para os antiqui: Tomás de Aquino, leitor de Agostinho. Princípios, Natal, v. 24, n. 43, p. 9-41, 2017a.

. A natureza da força: notas sobre o texto latino de In Physica II, 1, 1. 11-14 de Filopono. Philósophos, Goiânia, v. 22, n. 2, p. 125-151, $2017 \mathrm{~b}$.

- A cosmologia e cosmografia de Anaximandro no In de Caelo de Tomás de Aquino. Kriterion, Belo Horizonte, v. 59, n. 140, 2018 (no prelo).

THOMAS AQUINAS. In octo libros physicorum Aristotelis expositio. Opera omnia iussu impensaque Leonis XIII P. M. edita, vol. II, Roma: Typographia Polyglotta, 1884.

. In libros Aristotelis De caelo et mundo. Opera omnia iussu impensaque Leonis XIII P. M. edita, vol. III, Roma: Typographia Polyglotta, 1886.

Pars prima Summae Theologiae a quaestione I ad quaestionem XLIX. Opera omnia iussu impensaque Leonis XIII P.M. edita, vol. IV. Roma: Typographia Polyglotta, 1888.

. Quaestiones Disputatae de Potentia Dei. Ed. P. Mandonnet, vol. II, Parisiis: P. Lethielleux, 1925.

. Scriptum Super Libros Sententiarum Magistri Petri Lombardi. Ed. P. Mandonnet Vol. 1-2, Parisiis: P. Lethielleux, 1929. 
Summa contra gentiles. Ed. Leon., vol. XIII-XV. Roma: Apud Sedem Commissionis Leoninae, 1934.

. Super Boetium De Trinitate. Opera omnia iussu Leonis XIII P. M. Edita, vol. L, Commissio Leonina - Roma - Paris: Éditions du Cerf, 1992.

Quaestio Disputata De Spiritualibus Creaturis. Ed. J. COS. Ed. Leon., vol. XXIV-2. Roma - Paris: Commissio Leonina - Les Éditions du Cerf, 2000.

TWETTEN, David B. “Why Motion Requires a Cause: The Foundation for a Prime Mover in Aristotle and Aquinas". In: LONG, James (ed.). Philosophy and the God of Abraham: Essays in Memory of James A. Weisheipl, O.P. Toronto: Pontifical Institute of Mediaeval Studies, 1991. p. 235-254. 243, 1996a.

Back to Nature in Aquinas. Medieval Philosophy and Theology, v. 5, p. 205-

. Clearing a 'Way' for Aquinas: How the Proof from Motion Concludes to God. Proceedings of the American Catholic Philosophical Association, v. 70, p. 259-278, $1996 \mathrm{~b}$.

Aquinas' Aristotelian and Dionysian Definition of 'God'. Thomist, v. 69, p. 203-250, 2005.

To Which 'God' Must a Proof of God's Existence Conclude for Aquinas?. In. HOUSER, R. E (ed.). Laudemus Viros Gloriosos: Essays in Honor of Armand Maurer. Notre Dame: University of Notre Dame Press, 2007. p. 146-183.

WEISHEIPL, J. A. Nature and Gravitation. River Forest, Illinois: Albertus Magnus Lyceum. 1955.

. The Development of Physical Theory in the Middle Ages. London, New York: Sheed and Ward, 1959.

. The Celestial Movers in Medieval Physics. The Thomist, 24, p. 286-326, 1961.

. The Principle Omne quod movetur ab alio movetur in Medieval Physics. Isis, v. 56, n. 1, p. 26-45, 1965.

The Spector of Motor Coniunctus in Medieval Physics. In: Studi sul XIV secolo in memoria di Anneliese Maier. Roma (Itália): Edizioni di storia e letteratura, 1981. p. 81-104.

. Aristotle's Concept of Nature: Avicenna and Aquinas. Medieval E Renaissance texts $\mathcal{E}$ studies: Center of Medieval $\mathcal{E}$ Early Renaissance Studies, Binghamton, New York, p. 137-169, 1982.

Endereço do Autor:

R. Travessa Castro Alves, n. 98 - Casas Populares,

48970-000 Senhor do Bonfim - BA

evanielbras@gmail.com 